\title{
Effect of contrast media on urinary cytopathology specimens
}

\author{
Sebastian Frees, MD; ${ }^{*}$ Samir Bidnur, MD; ${ }^{*}$ Michael Metcalfe, MD; ${ }^{*}$ Peter Raven, PhD; \\ Claudia Chavez-Munoz, MD, PhD; Igor Moskalev, MD; Ladan Fazli, MD; Alan So, MD
}

Department of Urologic Sciences, Vancouver Prostate Centre, University of British Columbia, Vancouver, BC, Canada

*Eual contributors

Cite as: Can Urol Assoc J 2016;10(7-8):228-33. htrp://dx.doi.org/10.5489/cuaj.3874

\section{Abstract}

Introduction: Urological dogma dictates that washings collected from the urinary tract for cytological assessment must be performed without interference from contrast agents that may alter cellular integrity and diagnostic interpretation. In practice, the initial contrast used to outline the upper tracts is commonly discarded with subsequent saline washings sent for cytology. We hypothesize that contrast washings do not affect the morphology of urothelial carcinoma cells or the integrity of cytology interpretation.

Methods: Samples obtained from (1) human bladder cell lines; (2) urine from a human xenograft bladder cancer model using UC-3 cells; and (3) patients with urothelial carcinoma were subjected to various experimental solutions (water, saline, urine, and dilutions of contrast media) for different exposure times. After exposure to various different solutions, samples underwent cytological analysis to assess morphologic and degenerative changes.

Results: No cytological differences were seen when cells were exposed to ionic, hyperosmolar, or non-ionic low-osmolar contrast agents for any exposures up to five minutes. Cells exposed to mixtures of contrast agents and urine also demonstrated no evidence of degenerative change. Cells exposed to water for greater than one minute demonstrated significant hydropic degeneration impacting cytological interpretation. At 40 minutes or later, all reagents caused severe degeneration when evaluating urine samples from the mouse bladder cancer model and from patients undergoing urothelial carcinoma.

Conclusions: Commonly used contrast agents have no effect on urinary cytology up to five minutes. Contrast washings of the urinary tract should not be discarded and can be sent for cytological diagnosis if fixed within this time period.

\section{Introduction}

Upper tract urothelial carcinoma (UTUC) of the renal pelvis or ureter account for $5 \%$ of all urological tumours, with an increasing frequency over the last decade. ${ }^{1,2}$ Early detection of UTUC with a combination of imaging studies and urinary cytological assessment has led to a stage migration, changing five-year survival rates from only $16.5 \%$ in distant disease to $95 \%$ in in-situ disease. ${ }^{2}$

Urine cytology is an important modality for detection, assessment, and followup of UTUC. Cytology, in conjunction with cystoscopy and/or ureteroscopy is the gold standard for evaluation and investigation of upper urinary tract filling defects. Urine cytology is accurate for the diagnosis of high-grade UTUC, with specificities as high as $98 \%$ and sensitivities of $79 \%$, with lower sensitivity for low-grade disease. ${ }^{3-6}$ However, many factors have been shown to decrease the sensitivity and specificity of urinary cytology, including: low tumour grade, instrumentation, number and methods of collection, background hematuria and inter-pathologist variability. ${ }^{6-10}$ The effect of contrast agents has also been investigated with conflicting results; the current urological dogma is to discard contrast washings after retrograde pyelography and obtain washings in saline to maintain the diagnostic accuracy of cytology. ${ }^{11}$ To address this issue, we designed a study to assess whether commonly used contrast agents affect cellular morphology or hinder interpretation of urinary cytology specimens. Specifically, we subjected urinary carcinoma $(U C)$ cell lines, urine from orthotopic murine UC xenografts, and human urine to multiple experimental solutions at variable time points, comparing the effect of contrast media on the cytological interpretation.

\section{Methods}

\section{Cell culture}

Human urothelial cell lines were obtained from ATCC (Manassas, VA, U.S.). These included SV-HUC, a benign 
human urothelial cell line, UM-UC-3, a low-grade and RT-4, a high-grade UC cell line, respectively. Cells were cultured in MEM (Gibco, Carlsbad, CA, U.S.) supplemented with L-glutamine (Gibco, Carlsbad, CA, U.S.), non-essential amino acid solution (Gibco, Carlsbad, CA, U.S.), 1 mM sodium pyruvate (Gibco, Carlsbad, CA, U.S.), and 10\% fetal bovine serum (Gibco, Carlsbad, CA, U.S.) for three days. Cells were then collected in phosphate-buffered saline (PBS) at a concentration of $10^{4}$ cells $/ \mathrm{mL}$ and subjected to experimentation

\section{Sample treatment design}

Each sample (cell lines, mouse urine, and human urine) was reconstituted into $1 \mathrm{~mL}$ of each of seven experimental solutions. The experimental solutions included: 1) sterile distilled water $\left.\left(\mathrm{dH}_{2} \mathrm{O}\right) ; 2\right) 0.9 \%$ sterile normosaline solution; 3$)$ urine; 4) Conray ${ }^{\mathrm{TM}}$ (iothalamate meglumine $60 \%$, monobasic sodium 12.5\%, Mallinkckrodt Pharmaceuticals, Chesterfield, UK) $100 \%$; 5) Conray ${ }^{\mathrm{TM}} 50 \%$, saline $50 \%$; 6) Ominpaque ${ }^{\mathrm{TM}}$ (iohexol 70\%, GE Healthcare Ireland, Cork, Ireland) 100\%; and 7) Omnipaque ${ }^{\mathrm{TM}} 50 \%$, saline $50 \%$.

Each sample was exposed to each of the solutions for four time points: one, five, $40 \mathrm{~min}$ and 24 hours. All exposure times were done in triplicates. Once exposure was completed, $1 \mathrm{~mL}$ fixative solution (97\% methanol, 3\% acetone) was used to preserve the samples and they were stored at $4{ }^{\circ} \mathrm{C}$ for further pathological evaluation, including hematoxylin and eosin (H\&E) staining, followed by interpretation. All in-vitro experiments were performed in triplicate and repeated three independent times.

\section{UM-UC3 luciferase-expressing cells}

For animal studies, the UM-UC3 cells were transduced with a lentiviral construct carrying the luciferase firefly gene for further in-vivo imaging; and blasticidin resistance gene for positive selection achieved with $10 \mu \mathrm{g} / \mathrm{mL}$ blasticidin (Life Technologies Inc., Burlington, ON, Canada). ${ }^{12}$ In-vitro, luciferase activity was confirmed and cell number was correlated with bioluminescence $(R>0.99)$ using the Xenogen IVIS Spectrum (Caliper Lifesciences, Hopkinton, MA, U.S.).

\section{Orthotopic murine xenograft muscle invasive bladder cancer model ${ }^{13}$}

All animal procedures were performed according to the guidelines of the Canadian Council on Animal Care (CCAC). The protocol was approved by the University of British Columbia animal care committee (protocol number A100192). Briefly, five 10-week-old female athymic nude mice (Harlan Labs, Indianapolis, IN, U.S.) were anesthetized and UM-UC3 luciferase firefly-expressing cells were suspended in Matrige ${ }^{\circledR}$ (BD Biosciences, Mississauga, ON, Canada) and injected into the submucosa of the bladder wall via ultra- sound guidance ${ }^{13}$ (Fig. 1A). Bladder tumours were followed with serial high-frequency RMV 706 small animal ultrasound scanhead (Vevo770, Visual Sonics, Toronto, ON, Canada) and bioluminescence imaging (Xenogen IVIS Spectrum, Caliper Lifesciences, Hopkinton, MA, U.S.) (R >0.99) (Fig. 1B). Fresh urine was collected, $2-3$ weeks post-implantation of bladder tumours and pooled on ice until subjected to the same seven experimental solutions as stated above. For mouse samples, $50 \mu \mathrm{L}$ of fresh urine was combined with 50 $\mu \mathrm{L}$ of each experimental solution. Samples were fixed with $97 \%$ methanol and 3\% acetone after the abovementioned time points and stored at $4^{\circ} \mathrm{C}$ until pathology evaluation.

\section{Human urine samples}

Urine samples were collected from four patients with muscle-invasive bladder cancer undergoing cystectomy and one patient prior to transurethral resection. All patients had positive urine cytology showing high-grade urothelial cells prior to surgery. Urine was subjected to the seven experimental conditions and time points described above. One $\mathrm{mL}$ of fresh urine was reconstituted in the solutions and volumes as mentioned above, fixed with the same fixative solution ( $97 \%$ methanol, $3 \%$ acetone), and stored at $4{ }^{\circ} \mathrm{C}$ until pathology evaluation.

\section{Cytology}

Each fixed specimen was assessed following H\&E staining by an uropathologist with subspecialty training in cytopathology (L.F.). The pathologist was blinded to the treatment groups. Specimens were analyzed for morphology and degenerative changes, including hydropic degeneration characterized by cytoplasmic loss or vacuolization and increased cytoplasmatic granularity. Slides for cytological interpretation were scored based on the amount of degeneration present. For invitro cell line interpretation, the pathologist also commented on the ability to differentiate benign cells from cancerous tumour cells. All slides were imaged using a Leica microscope at 40x magnification.

\section{Results}

The three urothelial cell lines (SV-HUC, UM-UC-3, and RT-4) were exposed to all seven experimental solutions and analyzed at one, five, 40 minutes, and 24 hours (Fig. 2 , Table 1). No morphological changes affecting cytological interpretation were noted among the urine, saline, Conray, and Omnipaque (both $50 \%$ and $100 \%$ ) groups at time points up to five minutes. Only the $\mathrm{dH}_{2} \mathrm{O}$ group demonstrated severe hydropic degenerative change at all time points, resulting in the inability to discriminate benign vs. malignant cells or grade of malignancy (low vs. high). The 
Frees et al.

Table 1. Human UC cell lines

\begin{tabular}{|c|c|c|c|c|c|c|c|c|c|c|c|c|c|c|c|c|c|c|c|c|}
\hline \multirow{3}{*}{ Cell line } & \multicolumn{4}{|c|}{ Urine } & \multicolumn{4}{|c|}{ Saline } & \multicolumn{4}{|c|}{ Water } & \multicolumn{4}{|c|}{ Conray } & \multicolumn{4}{|c|}{ Omnipaque } \\
\hline & 1 & 5 & 40 & 24 & 1 & 5 & 40 & 24 & 1 & 5 & 40 & 24 & 1 & 5 & 40 & 24 & 1 & 5 & 40 & 24 \\
\hline & \multicolumn{3}{|c|}{$\min }$. & $\mathbf{h}$ & \multicolumn{3}{|c|}{$\min }$. & $\mathbf{h}$ & \multicolumn{3}{|c|}{$\min }$. & $\mathbf{h}$ & \multicolumn{3}{|c|}{$\min }$. & h & \multicolumn{3}{|c|}{$\min$. } & h \\
\hline
\end{tabular}

\section{SV-HUC}

UC-3 Intact Degeneration Intact Degeneration HD Intact Degeneration Intact Degeneration

RT-4

\begin{tabular}{|c|c|c|c|c|c|c|c|}
\hline \multirow{3}{*}{ Cell line } & \multicolumn{3}{|c|}{$\begin{array}{c}\text { Conray/Saline } \\
50: 50\end{array}$} & \multicolumn{4}{|c|}{$\begin{array}{c}\text { Omnipaque/Saline } \\
50: 50\end{array}$} \\
\hline & 1 & 40 & 24 & 1 & 5 & 40 & 24 \\
\hline & \multicolumn{2}{|r|}{$\min }$. & $\mathbf{h}$ & \multicolumn{3}{|c|}{$\min }$. & $\mathbf{h}$ \\
\hline
\end{tabular}

UC-3 Intact Degeneration Intact Degeneration

RT-4

Three cell lines representing benign urothelium to aggressive urothelial carcinoma were subject to seven different experimental solutions at four different time points, with results demonstrated above. Primary outcome is the effect of any experimental solution on cellular morphology and cytopathological integrity. Hydropic degeneration (HD) is characterized by cellular changes limiting cytology interpretation including vacuolization and loss of cytoplasm. Both benign (SV-HUC) and malignant (UC-3, RT-4) demonstrate similar changes, with intact

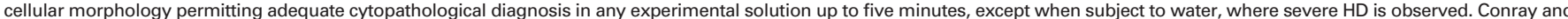

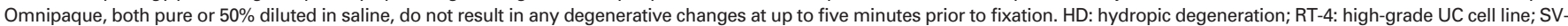
HUC: benign urothelial cell line; UC: urothelial carcinoma; UC-3: intermediate-grade urothelial carcinoma.

hydropic degeneration was characterized by cytoplasmic loss or vacuolization and increased cytoplasmic granularity. Interestingly, our results demonstrated that all cells subjected to any experimental condition for more than five minutes also demonstrated cellular degeneration (images not shown in the panel).

The orthotopic murine xenograft muscle-invasive bladder cancer model confirmed these results (Fig. 1, Table 2). All mice had high-volume UM-UC-3-luc bladder tumours, as assessed by ultrasound and IVIS, resulting in significant background hematuria. All mice urine samples were exposed to the same conditions as mentioned before, but assessed at one and five minutes only. This was mostly due to limitations in sample volume. Results showed that the exposure to the different conditions did not alter cytological assessment, with exception of the water-treated samples showing degenerative changes (Table 2).

The human samples demonstrated similar results to the in-vitro and animal study arms. There was no degenerative change in either contrast media or saline at one and five minutes. However, at and beyond 40-minute time exposure, degeneration was observed, regardless of the reagent exposed. Confirming previous experiments, only exposure to water showed major degenerative changes limiting cytological assessment, regardless of time point (Fig. 3, Table 3).

\section{Discussion}

This study demonstrates that commonly used contrast agents do not alter urothelial cell morphology at exposures up to five minutes prior to fixation. Regardless of whether the urothelial cells were washed with contrast or saline, no differences were observed in cellular morphology or in pathologist ability to correctly differentiate benign from malignant
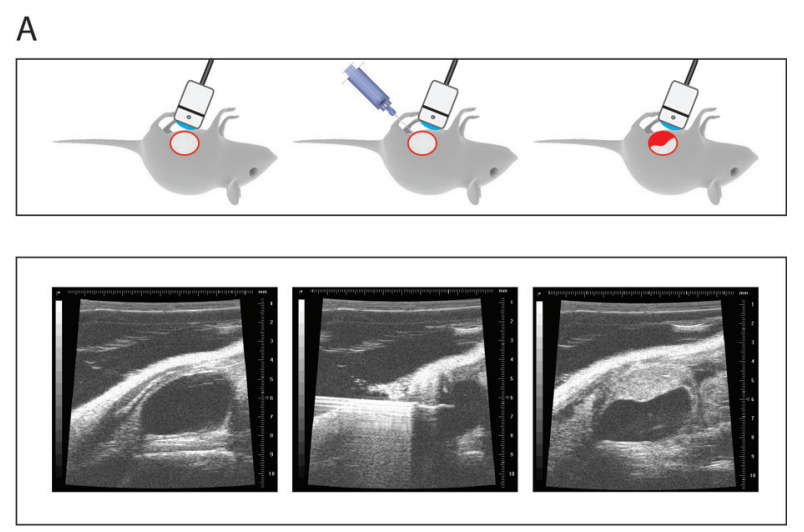

B

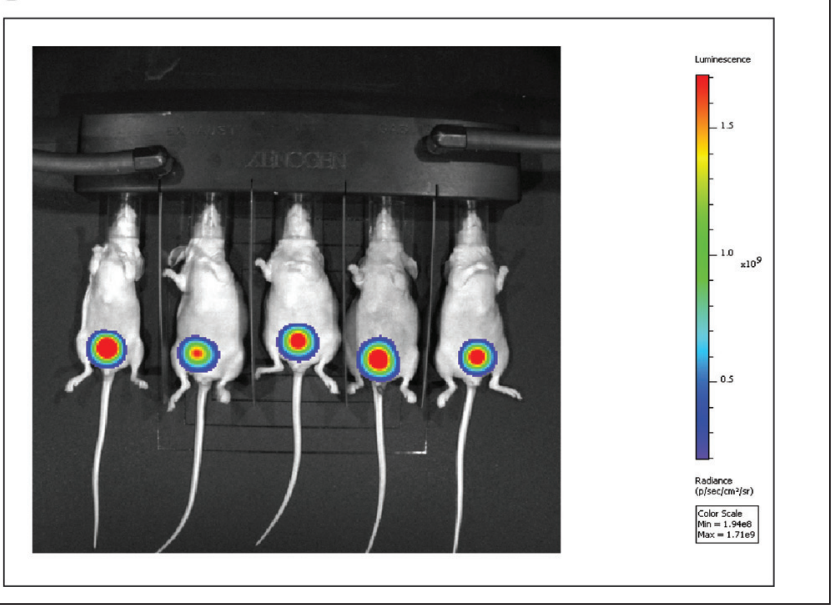

Fig.1. Orthotopic bladder cancer mouse model. (A) Schematic representation of methods of establishing orthotopic UM-UC-3-luc murine xenograft. Under ultrasound guidance, a $30 \mathrm{~g}$ needle is introduced percutaneously into the bladder of anesthetized mice and 5x105 cells are injected; (B) Tumours are followed with serial ultrasound and imaging using the IVIS system, visualizing and quantifying the luciferase positive UM-UC-3 cells, confirming intravesical tumour growth. 


\begin{tabular}{|c|c|c|c|c|c|c|c|c|c|c|}
\hline \multirow{4}{*}{$\begin{array}{l}\text { Bladder cancer } \\
\text { mouse model }\end{array}$} & \multicolumn{2}{|c|}{ Urine } & \multicolumn{2}{|c|}{ Saline } & \multicolumn{2}{|c|}{ Water } & \multicolumn{2}{|c|}{ Conray } & \multicolumn{2}{|c|}{ Omnipaque } \\
\hline & 1 & 5 & 1 & 5 & 1 & 5 & 1 & 5 & 1 & 5 \\
\hline & \multicolumn{2}{|c|}{$\min$} & \multicolumn{2}{|c|}{$\min$} & \multicolumn{2}{|c|}{$\min$} & & & \multicolumn{2}{|c|}{$\min$} \\
\hline & \multicolumn{2}{|c|}{ Intact } & \multicolumn{2}{|c|}{ Intact } & HD, $80 \%$ of cells & HD, $95 \%$ of cells & & & & \\
\hline \multirow{3}{*}{$\begin{array}{l}\text { Bladder cancer } \\
\text { mouse model }\end{array}$} & \multicolumn{2}{|c|}{ Conray/Saline 50:50 } & \multicolumn{2}{|c|}{ Omnipaque/Saline 50:50 } & & & & & & \\
\hline & 1 & 5 & 1 & 5 & & & & & & \\
\hline & \multicolumn{2}{|c|}{$\min$} & \multicolumn{2}{|c|}{$\min$} & & & & & & \\
\hline Urine & \multicolumn{2}{|c|}{ Intact } & \multicolumn{2}{|c|}{ Intact } & & & & & & \\
\hline
\end{tabular}

cytology. Further, exposure times longer than five minutes resulted in significant cellular degeneration. These results suggest that contrast media do not confound cytological interpretation of upper tract washings and do not need to be discarded as long as fixation occurs within five minutes following collection. Protocols for optimal fixation of urine samples to preserve cellular integrity for prolonged periods use high concentration of either methanol or ethanol. ${ }^{14,15}$

The effect of contrast media on urinary tract cytology has been studied previously, but conflicting results on its effects on cellular integrity has led to the popular practice of discarding urine samples taken after retrograde pyelography performed to delineate upper tract anatomy. Concern for the effect of contrast media on the cellular architecture of urothelial cells was first described during the 1970s. ${ }^{16-18}$ This was followed by the demonstration that low-osmolar, nonionic agents may affect morphology less than conventional high-osmolar agents. ${ }^{19}$ This notion was reinforced more recently by Terris in 2003, where exposure of urothelial

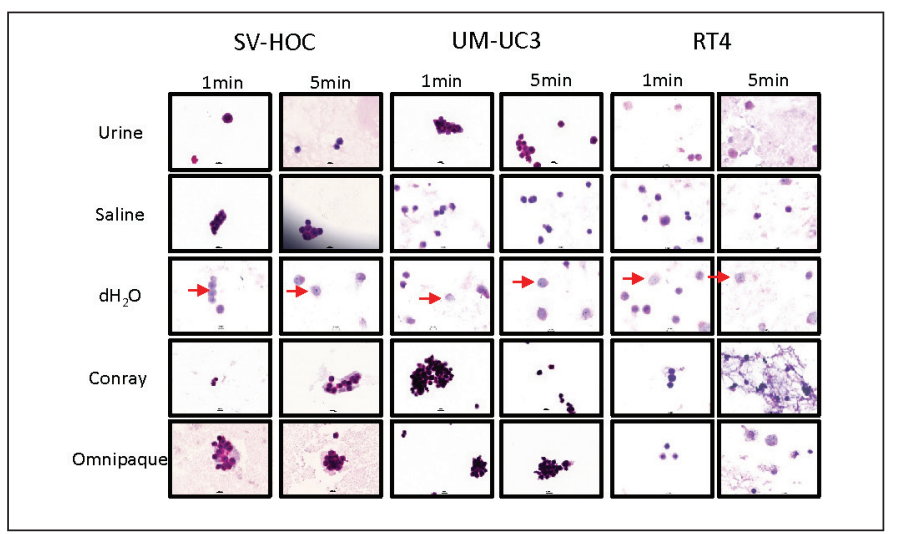

Fig. 2. SV-HUC, UM-UC-3 and RT-4 cell lines exposed to the different treatments for up to five minutes. $\mathrm{dH} 2 \mathrm{O}$ : hydropic degeneration in the form of vacuolization of the cytoplasm, granulation, and total loss of cytoplasm (arrows showing these changes). Urine: clusters of urothelial cancer cells have high nuclear-to-cytoplasm ratios, the nuclear border is intact, dense chromatin pattern is present, no shrinkage, piknosis, vacuolation, naked nuclei, fragments. Conray and Omnipaque do not show any artifacts or cell morphology alterations other than appropriate to cancer cells (panel showing representative images). cells to ionic, high-osmolar contrast agents reduced viability and adherence of urothelial cells. ${ }^{20}$ This has consolidated the belief that contrast should be limited during retrograde pyelography due to fear of damaging the cytopathological specimen and possibly increasing the false negative rate. Several studies have demonstrated the value of using initial contrast washings for urinary cytology. A study of 19 patients by Barry et al was first to demonstrate that routine contrast media washings, in addition to saline washings, may aid in detection of malignancy and should, therefore, not be routinely discarded. ${ }^{21}$ Importantly, this study paired contrast and saline washings from each patient; of seven patients with urothelial malignancy, only three contrast washings were diagnostic. The remainder required assessment of the saline washing to confirm malignancy.

In contrast to our results, Andriole et a $\mathrm{I}^{19}$ reported a difference in the influence of ionic and non-ionic contrast agents. They showed that ionic contrast agents, such as Conray ${ }^{\mathrm{TM}}$, caused a higher rate of cytological artifacts, with increasing concentration of the contrast agent. Only seven of their 33 patients showed UC cells in cytology. However, the exposure time (15-60 minutes) was longer than the one used in our study, which may explain differences with our experiment.

In our study, we manipulated two variables that are important for the quality of cytological interpretation: the washing solution and time to fixation. The influence of time to fixation on quality of cytological interpretation has also been previously described, suggesting that early fixation of urine results in better quality of staining. ${ }^{22}$ We noted major disruption of cellular architecture at time points after five minutes. We hypothesize that the changes in osmolarity and $\mathrm{pH}$ in combination with the exposure time account for the observed degeneration.

There are substantial false-negative or false-positive results associated with ureteral catheterization for collection of upper tract washings. ${ }^{10}$ Many factors affect urine cytology and decrease its sensitivity ${ }^{6-8}$ Saline washing, brush biopsy through a retrograde catheter, or ureteroscopy may improve sensitivity and specificity each to approximately $90 \% .{ }^{5,21}$ However, brush biopsy is associated with higher risk of severe complications. ${ }^{23}$ 
Frees et al.

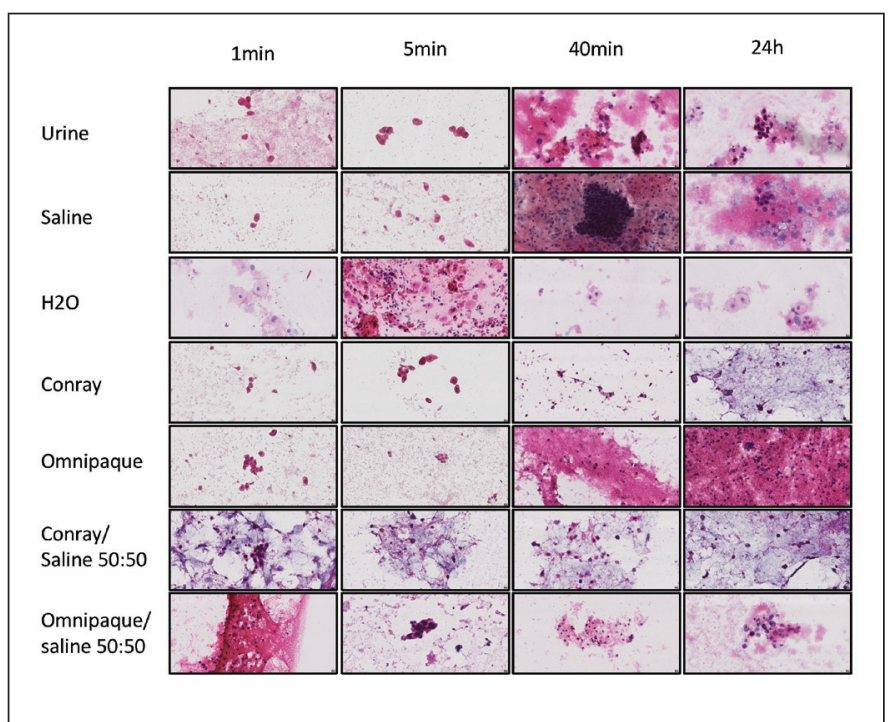

Fig. 3. Human urine from patients with muscle invasive bladder cancer undergoing cystectomy or transurethral resection. Urines from four bladder cancer patients were collected and subjected to all treatments $(\mathrm{dH} 2 \mathrm{O}$, saline, Conray, Omnipaque, and left in urine). Only samples subjected to $\mathrm{dH} 20$ show hydropic degeneration in form of vacuolization of the cytoplasm, granulation, and total loss of cytoplasm at all-time points (indicated by arrows). However, at 40-minute time exposure, degeneration was observed, regardless of the reagent exposed (panel showing representative images).

This study gives the first full methodological approach of the influence of contrast media on urine cytology. We demonstrate that using various sources of urothelial cancers, including human cell lines, an animal xenograft bladder cancer model, and human samples, contrast media is safe to use for cytology if fixed early. Limitations of this study include the lack of an objective measure of cellular change and a single study pathologist. To isolate the effect of contrast medium from other confounding factors during upper tract washes, we did not perform actual washes, but wanted to emphasize on the most standardized approach possible. However, as water acts as the positive control for degeneration, it allows for a more sensitive assessment of degeneration in the contrast arms.
Our study adds to the body of evidence concluding that initial contrast washings of the urinary tract should not be discarded and that sloughed cells collected in these washings can be valuable for cytological interpretation.

\section{Conclusion}

Washings of the urinary tract with commonly used contrast agents does not impair cytopathological analysis of urinary cytology when fixed within five minutes. Longer exposure should be avoided due to increasing cell degeneration.

Competing interests: Dr. So has been a Speakers' Bureau member for Amgen, Astellas, and Janssen. The remaining authors report no competing personal or financial interests.

This paper has been peer-reviewed.

\section{References}

1. David KA, Mallin K, Milowsky Ml et al. Surveillance of urothelial carcinoma: Stage and grade migration, 1993-2005 and survival trends, 1993-2000. Cancer 2009;115:1435-47. http://dx.doi. org/10.1002/cncr.24147

2. Munoz JJ, Ellison LM. Upper tract urothelial neoplasms: incidence and survival during the last 2 decades. J Urol 2000; 164:1523-5. http://dx.doi.org/10.1016/S0022-5347(05)67019-X

3. Bastacky $S$, lbrahim $S$, Wilczynski $S P$, et al. The accuracy of urinary cytology in daily practice. Cancer 1999;87:118-28. http://dx.doi.org/10.1002/(SICI) 1097-0142(19990625)87:3<1 18::AIDCNCR4>3.0.C0;2-N

4. Beyer-Boon ME, de Voogt HJ, van der Velde EA, et al. The efficacy of urinary cytology in the detection of urothelial tumours. Sensitivity and specificity of urinary cytology. Urol Res 1978;6:3-12. http://dx.doi. org $/ 10.1007 /$ BF00257076

5. Halling KC, King W, Sokolova IA, et al. A comparison of cytology and fluorescence in situ hybridization for the detection of urothelial carcinoma. J Urol 2000;164:1768-75. http://dx.doi.org/10.1016/ S0022-5347(05)67104-2

6. Raab SS, Grzybicki DM, Vrbin CM, et al. Urine cytology discrepancies: frequency, causes, and outcomes. Am I Clin Pathol 2007;127:946-53. http://dx.doi.org/10.1309/XUVXFXMFPL7TELCE

7. Sherman AB, Koss LG, Adams SE. Inter-observer and intra-observer differences in the diagnosis of urothelial cells. Comparison with classification by computer. Anal Quant Cytol 1984,6:112-20.

8. Todenhofer T, Hennenlotter J, Tews V, et al. Impact of different grades of microscopic hematuria on the performance of urine-based markers for the detection of urothelial carcinoma. Urol Oncol 2013;31:114854. http://dx.doi.org/10.1016/i.urolonc.2011.10.011

Table 3. Urine sample from UC patients

\begin{tabular}{|c|c|c|c|c|c|c|c|c|c|c|c|c|c|c|c|c|c|c|c|c|}
\hline \multirow{3}{*}{ Human samples } & \multicolumn{4}{|c|}{ Urine } & \multicolumn{4}{|c|}{ Saline } & \multicolumn{4}{|c|}{ Water } & \multicolumn{4}{|c|}{ Conray } & \multicolumn{4}{|c|}{ Omnipaque } \\
\hline & 1 & 5 & 40 & 24 & 1 & 5 & 40 & 24 & 1 & 5 & 40 & 24 & 1 & 5 & 40 & 24 & 1 & 5 & 40 & 24 \\
\hline & \multicolumn{3}{|c|}{$\min }$. & $\mathbf{h}$ & \multicolumn{3}{|c|}{$\min }$. & $\mathbf{h}$ & \multicolumn{3}{|c|}{$\min }$. & $\mathbf{h}$ & \multicolumn{3}{|c|}{$\min }$. & h & \multicolumn{3}{|c|}{$\min }$. & $\mathbf{h}$ \\
\hline Urine & & act & Deg & ration & & act & Deg & eration & & & & & & act & Deg & eration & & act & Deg & ration \\
\hline \multirow{3}{*}{ Human samples } & \multicolumn{4}{|c|}{$\begin{array}{c}\text { Conray/Saline } \\
50: 50\end{array}$} & \multicolumn{4}{|c|}{$\begin{array}{c}\text { Omnipaque/Saline } \\
50: 50\end{array}$} & & & & & & & & & & & & \\
\hline & 1 & 5 & 40 & 24 & 1 & 5 & 40 & 24 & & & & & & & & & & & & \\
\hline & \multicolumn{3}{|c|}{$\min }$. & $\mathbf{h}$ & \multicolumn{3}{|c|}{$\min }$. & $\mathbf{h}$ & & & & & & & & & & & & \\
\hline Urine & & tact & Deg & ration & & act & Deg & eration & & & & & & & & & & & & \\
\hline
\end{tabular}

Urine from four patients, three undergoing cystectomy, and one undergoing TURBT, all with positive preoperative cytology was collected via sterile catheterization and subject to seven

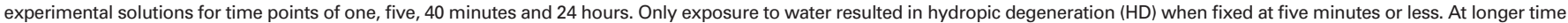
points of 40 minutes or longer, degenerative changes are observed across all experimental solutions. 
9. Todenhofer $\mathrm{T}$, Hennenlotter J, Witstruk $M$, et al. Influence of renal excretory function on the performance of urine-based markers to detect bladder cancer. J Urol 2012;187:68-73. http://dx.doi.org/10.1016/i. juro.2011.09.023

10. Zincke H, Aguilo JJ, Farrow GM, et al. Significance of urinary cytology in the early detection of transitional cell cancer of the upper urinary tract. J Urol 1976;116:781-3.

11. Kavoussi L, Partin A, Novick A, et al. Cambell-Walsh Urology, 10 ed: Elsevier, 2010.

12. Hadaschik BA, Black PC, Sea JC, et al. A validated mouse model for orthotopic bladder cancer using transurethral tumour inoculation and bioluminescence imaging. BJU Int 2007;100:1377-84. http://dx.doi.org/10.1111/i.1464-410X.2007.07165.x

13. Jager W, Moskalev I, Janssen C, et al. Ultrasound-guided intramural inoculation of orthotopic bladder cancer xenografts: A novel high-precision approach. PLoS One 2013;8:e59536. http://dx.doi.org/10.1371/ journal.pone.0059536

14. Hermansen DK, Melamed MR, Coon JS, et al. Ethanol fixation of bladder irrigation specimens for flow cytometric analysis. A multi-institutional study from the bladder cancer flow cytometry network. Cancer 1989;63:1780-3. http://dx.doi.org/10.1002/1097-0142(19900501)63:9<1780::AlDCNCR2820630921>3.0.C0;2-0

15. Pearson JC, Kromhout L, King EB. Evaluation of collection and preservation techniques for urinary cytology. Acta Cytol 1981;25:327-33.

16. McAlister WH, Shackleford GD, Kissane J. The histologic effects of some iodine-containing contrast media on the rat peritoneal cavity. Radiology 1972;105:581-2. http://dx.doi.org/10.1148/105.3.581
17. Siu CM, Dunbar JS, Wright VJ, et al. Contrast media used in cystourethrography. Experimental evaluation. Invest Urol 1975;12:434-41.

18. McClennan BL, Oertel YC, Malmgren RA, et al. The effect of water-soluble contrast material on urine cytology. Acta Cytol 1978;22:230-3.

19. Andriole GL, MCClennan BL, Becich MJ, et al. Effect of low-osmolar, ionic and non-ionic, contrast media on the cytological features of exfoliated urothelial cells. Urol Radiol 1989;11:133-5. http://dx.doi. org/10.1007/BF02926496

20. Terris MK. The effect of contrast material on transitional cell carcinoma viability. Adv Exp Med Biol 2003:539:121-8. http://dx.doi.org/10.1007/978-1-4419-8889-8_10

21. Barry JM, Murphy JB, Nassir E, et al. The influence of retrograde contrast medium on urinary cytodiagnosis: A preliminary report. J Urol 1978; 119:633-4.

22. Ahmed HG, Tom MA. The consequence of delayed fixation on subsequent preservation of urine cells. Oman Med J 2011;26:14-8. http://dx.doi.org/10.5001/omi.2011.04

23. Blute RD Jr, Gittes RR, Gittes RF. Renal brush biopsy: Survey of indications, techniques, and results. J Urol 1981;126:146-9.

Correspondence: Dr. Alan So, Department of Urologic Sciences, University of British Columbia, Vancouver, BC, Canada; dralanso@mail.ubc.ca 